\title{
Dosage Adjustment of Irinotecan in Patients with UGT1A1 Polymorphisms: A Review of Current Literature
}

\author{
Lia Argevani, PharmD Candidate ${ }^{1}$; Caren Hughes, PharmD, MBA, BCOP²; Michael J. Schuh, PharmD, MBA, FAPhA²
}

${ }^{1}$ University of Florida College of Pharmacy; ${ }^{2}$ Mayo Clinic Florida

\begin{abstract}
Objective: To review available literature regarding pharmacogenomics (PGX) effects on the metabolism of irinotecan by the UGT1A1 gene and the resulting dose adjustments based on PGx genetic variant.

Summary: Irinotecan is a chemotherapy agent commonly used in treatment of various cancers such as metastatic colorectal cancer ( $m C R C)$ and others. The extent of decreased function of UGT1A1 varies based on genotype so irinotecan dose adjustments may be needed. Those with UGT1A1 homozygous * $28 / * 28$ genotype may experience $70 \%$ reduction in activity, while heterozygous genotypes with *1/*28 may only experience $30 \%$ loss. UGT1A1*6 variants may also play a role in decreased function. The incidence of *28 and *6 alleles varies among ethnic populations resulting in the need for dosage adjustments to avoid toxicities.
\end{abstract}

Conclusion: These findings add to a growing body of literature that suggest patients with UGT1A1*28 or *6 variant alleles benefit from lower doses of irinotecan. However, due to the heterogeneity of currently available studies, more evidence that investigates various regimens in different patient populations is needed to determine the most appropriate dosing strategies. Although other factors, as well as efficacy considerations will likely influence clinical decision making, genotype may be an important factor when determining dose.

Keywords: UDP-glucuronosyltransferase, UGT1A1, irinotecan, pharmacogenomics, PGx, colorectal cancer, chemotherapy

\section{Introduction}

Irinotecan is a chemotherapy agent commonly used in treatment of various cancers such as metastatic colorectal cancer (mCRC) among others. Irinotecan is a prodrug and is converted into its active metabolite, $\mathrm{SN}-38$ via hydrolysis. SN38 is then inactivated by UDP-glucuronosyltransferase (UGT1A1) through glucuronidation. ${ }^{1}$ (Figure I) The UGT1A1 gene is diverse with over 135 genetic variants reported. ${ }^{2}$ UGT1A $1 * 1$ is the wild type allele and represents normal function, while other alleles such as $* 28$ and $* 6$ result in decreased function of the enzyme. These variant alleles are observed in conditions associated with hyperbilirubinemia such as Crigler-Najjar and Gilbert's syndrome, since UGT1A1 also plays a role in bilirubin metabolism. ${ }^{3}$ The extent of decreased function varies based on genotype. Those with homozygous *28/*28 genotype may experience $70 \%$ reduction in UGT1A1 activity, while heterozygous genotypes with $* 1 / * 28$ may only experience a $30 \%$ loss. ${ }^{4}$ The incidence of these two alleles varies among ethnic populations. The $* 28$ allele is more commonly found in Caucasians and African Americans, while the ${ }^{*} 6$ allele is often seen in Asian populations. ${ }^{5}$ (Table I) With decreased activity of UGT1A1, the serum concentration of SN-38 increases and leads to possible increased risk of toxicity such as severe neutropenia, hepatotoxicity or diarrhea. (Figure II)

Due to the pivotal role UGT1A1 plays in the metabolism of irinotecan, the FDA amended the package insert in 2005 to recommend a reduction in the initial dosage if patients are homozygous for the ${ }^{*} 28$ allele. ${ }^{6}$ Since then, many studies have emerged solidifying the relationship between UGT1A1 genotype and incidence of adverse effects with administration of irinotecan. A meta-analysis by Yang et al. ${ }^{7}$ analyzing 38 studies found that the odds ratio for severe toxicity for $* 28$ homozygous genotypes compared to wild type genotypes was 3.50 , while for $* 6$ homozygotes it was 3.03 . However, a lack of guidance exists to provide specific initial dosing recommendations for clinicians, resulting in a need to analyze currently available literature.

Corresponding author: Caren Hughes, PharmD, MBA, BCOP

Mayo Clinic Florida

hughes.caren@mayo.edu 
Figure I

Metabolism of Irinotecan<smiles>CC#CCOC(=O)C1=C2C=C(C(=O)OC1)c1nc3ccc(OC(=O)N4CCC(N5CCCCC5)CC4)cc3c(CC)c12</smiles>

Irinotecan<smiles>CCc1c2c(nc3ccc(O)cc13)-c1cc3c(c(=O)n1C2)COC(=O)[C@@]3(C)O</smiles>

SN-38 (active)

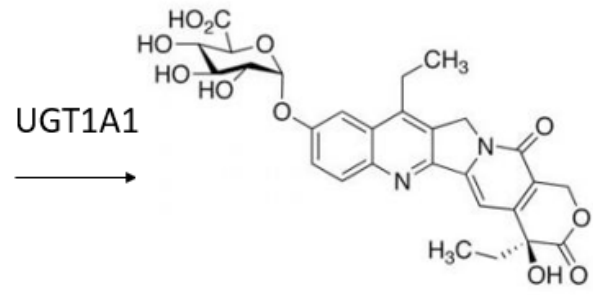

SN-38G (inactive)

Figure II

Concentration/Time SN-38G/SN-38 Ratio Profile of Genotypes

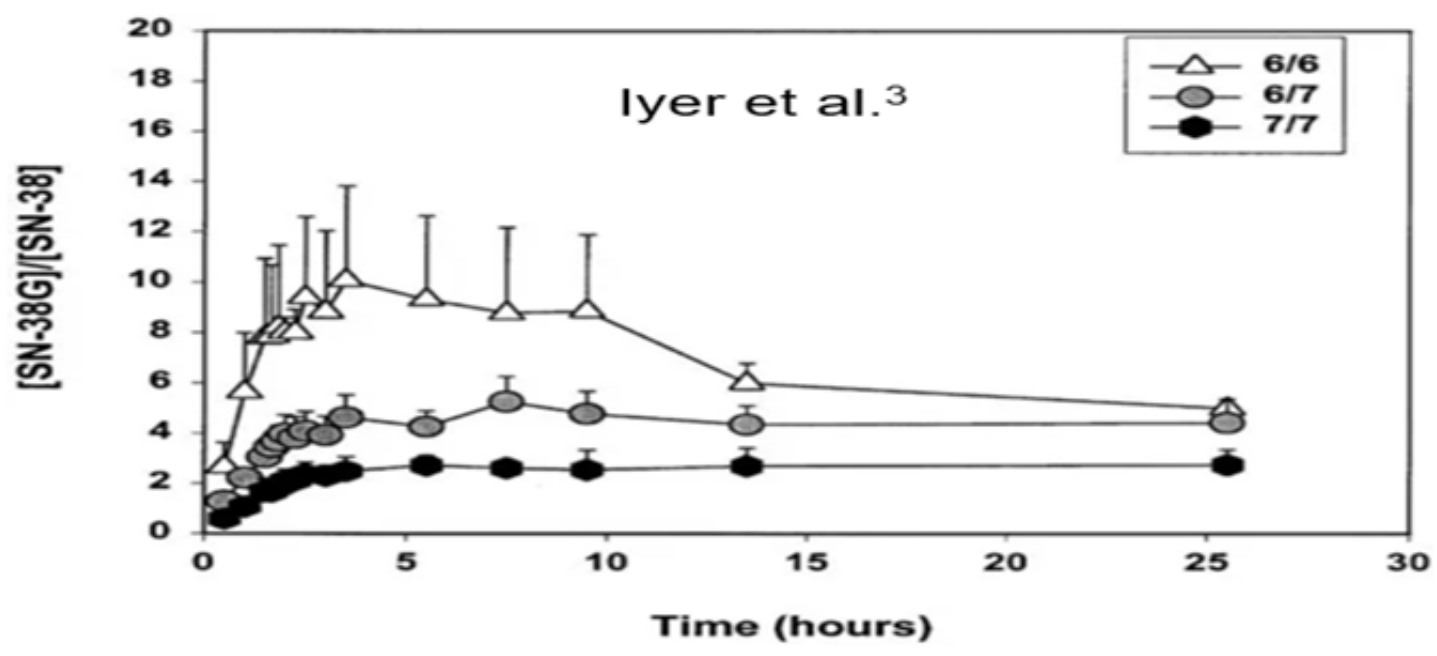

Key: $6 / 6=* 28 / * 28,6 / 7=* 1 / * 28, * 1 / * 1=7 / 7$

(\#Higher concentrations of SN-38 likely results in increased incidence of toxicity)

Table I

UGT1A1*28 and UGT1A1*6 Allele Frequencies

\begin{tabular}{|l|l|}
\hline \multicolumn{2}{|l|}{ UGT1A1*28 Allele Frequencies $^{\mathbf{4}}$} \\
\hline Caucasian & $0.26-0.31$ \\
\hline African American & $0.42-0.56$ \\
\hline Asian & $0.09-0.16$ \\
\hline UGT1A1*6 Allele Frequencies ${ }^{\mathbf{4}}$ \\
\hline Japanese & 0.13 \\
\hline Korean & 0.23 \\
\hline Chinese & 0.23 \\
\hline
\end{tabular}




\section{Methods}

The objective of the study was to gather and evaluate evidence available for appropriate irinotecan dosages in patients with *28 and *6 alleles to provide guidance for clinicians. A review of the literature was conducted in May 2019 using PubMed, Cochrane Library and Google Scholar, using the keywords "irinotecan", "UGT1A1", "dose-finding", "dose". Studies were evaluated based on inclusion and exclusion criteria described below. For each study, a single investigator performed data abstraction to include study population, sample size, genotype distribution, therapy regimen and primary/secondary endpoints.

Inclusion criteria:

- Treatment regimen included irinotecan

- $\quad$ Patients in experimental group had $* 28$ or $* 6$ alleles present

- Study evaluated effects of various doses on safety profile of irinotecan

- May be prospective or retrospective, but must include human subjects

- May take place in any country

- May include patients with any cancer type

Exclusion criteria:

- Study took place over 15 years ago

- Published in any other language other than English

- Only the abstract was available in publication

- Review article, editorials or opinion articles contained no original research

- Study only establishes relationship between genotype and incidence of adverse effects without consideration of dose

\section{Results}

Eight studies in total were included for analysis. ${ }^{8-15}$ All were phase I prospective dose finding studies except for Lu et al14 which was a retrospective chart review. Most of the studies included investigated patients with metastatic colorectal cancer, however two studies included patients with other types of malignancies. ${ }^{11,13}$ Goetz et al11 included patients with metastatic or locally advanced cancers with a variety of different tumor types such as breast, stomach and bladder. Innocenti et $\mathrm{al}^{13}$ studied patients with solid tumors or lymphomas refractory to standard therapy and tumor types were classified as gastrointestinal, lung or other. The sample size ranged from 48 to 107 participants. 6 out of 8 studies investigated the $* 1$ and $* 28$ alleles only. ${ }^{8,9,11,13-15}$ All included patients with $* 1 / 1, * 1 /{ }^{*} 28$ and $* 28 / * 28$ genotypes except the two studies by Toffoli et al ${ }^{8,15}$ who excluded $* 28 / * 28$ patients, due to low sample sizes. Satoh et al10 and Kim et al ${ }^{12}$ also included the $* 6$ variant allele, which is more prevalent in Asian countries. In Kim's study, there were two patients that displayed the $* 6 / * 28$ genotype, which they concluded would be functionally similar to a homozygous*28/*28 genotype. Inclusion criteria in all studies included parameters indicating adequate renal and hepatic function, such as serum creatinine less than $1.5 \mathrm{mg} / \mathrm{dL}$ and liver enzymes that were within normal limits. Some studies required patients to have an absolute neutrophil count (ANC) of greater than 1,500-2,000 to rule out pre-existing neutropenia. $8,9,11,12,13,15$ Other studies had additional criteria such as a wash-out period from prior chemotherapy or radiation that ranged from 3 weeks to 6 months to the time of study initiation. ${ }^{10-12}$

Finding the maximum tolerated dose (MTD) and dose limiting toxicities (DLT) was the primary endpoint in all studies. A 3+3 design (Figure III) was used in most studies to find MTD, except in Satoh et $\mathrm{al}^{10}$ which used the continual reassessment method (CRM) and Lu et $\mathrm{al}^{14}$ which was a retrospective chart review. Definitions of MTD varied between studies. Marcuello et $\mathrm{al}^{9}$ and Goetz et al $^{11}$ defined MTD as the dose level below which 2/6 patients experienced a DLT, while in Kim's study it was the level at which 2/6 patients experienced DLT. In Innocenti et al ${ }^{13}$, it was defined as the level at which less than 4/12 patients experience a DLT, mirroring a similar 33\% cutoff as the previous studies. In the 2010 study by Toffoli et $\mathrm{al}^{8}$, MTD was defined as the level at which <2/10 patients experience DLT but in his 2017 study, it was $<4 / 10$. Definitions for dose limiting toxicity were consistent between studies and included grade 3-4 diarrhea and neutropenia, as defined by the Common Terminology Criteria for Adverse Events. ${ }^{16}$ 
Figure III

Design Schematic for 3+3 Phase I Study ${ }^{1}$

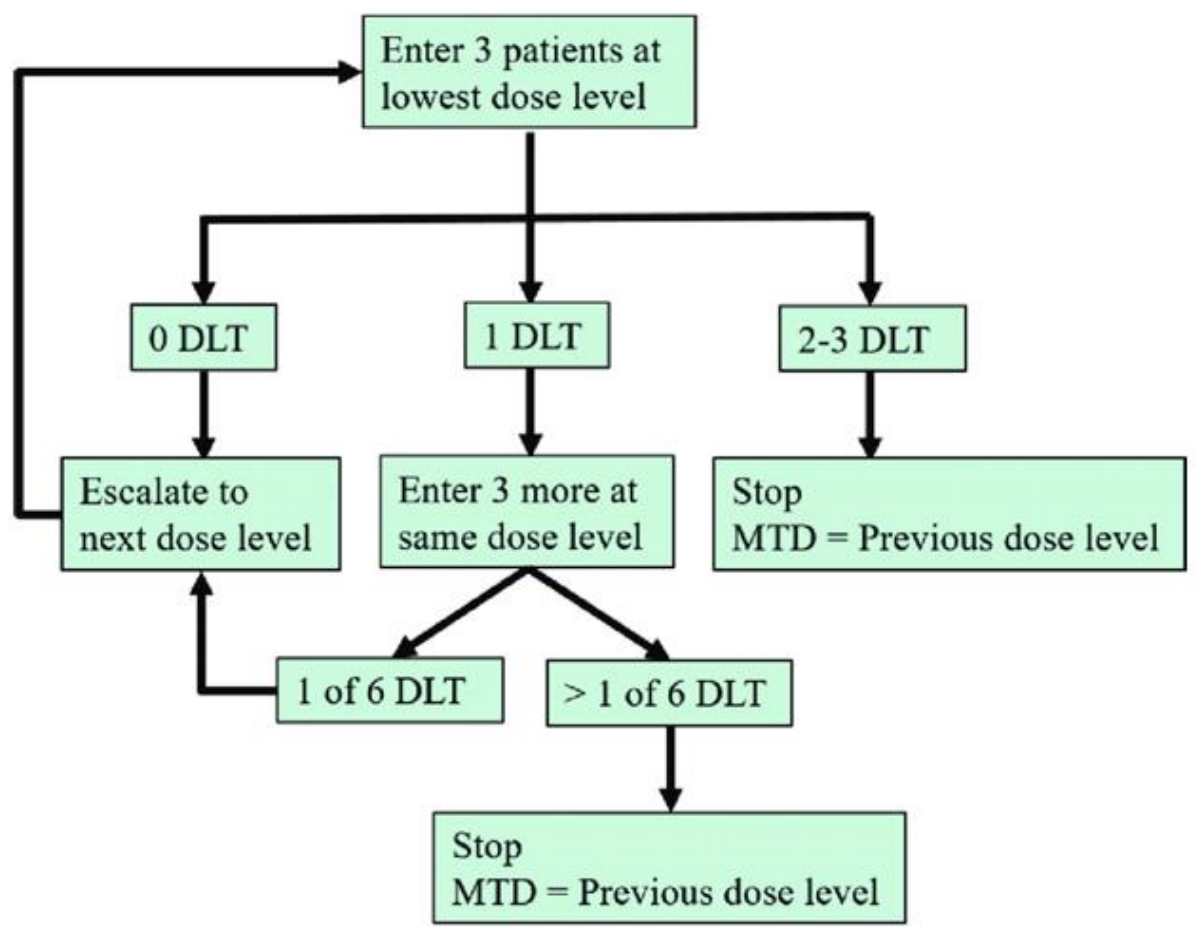

The studies varied in the regimen of irinotecan used. Irinotecan monotherapy was only used in two studies, although frequency was every 14 days in one study and every 21 days in the other. 10,13 Four studies used FOLFIRI, which is comprised of irinotecan administered every 2 weeks in combination with 5-fluorouracil and leucovorin. ${ }^{8,9,14,15}$ However, in two of those studies, bevacizumab was concomitantly used. 14,15 Two studies included capecitabine. ${ }^{11,12} \mathrm{Kim}$ et al ${ }^{12}$ studied XELIRI, which combines irinotecan and capecitabine alone while Goetz et al ${ }^{11}$ studied CAPIRINOX, where irinotecan is administered with capecitabine and oxaliplatin. Starting doses used for patients with homozygous variant alleles ranged from $75-240 \mathrm{mg} / \mathrm{m}^{2}$, depending on the regimen. The lowest MTD for $* 28 / * 28$ was reported in Marcuello et al $^{9}$ and Goetz et $\mathrm{al}^{11}$ at $90 \mathrm{mg} / \mathrm{m}^{2}$ and $75 \mathrm{mg} / \mathrm{m}^{2}$ respectively, although different regimens were used. Satoh et al $^{10}$ determined MTD to be $150 \mathrm{mg} / \mathrm{m}^{2}$ for $* 6$ and $* 28$ homozygous genotypes. Higher MTDs were observed in Lu et $\mathrm{al}^{14}$ and Kim et al. ${ }^{12}$ Lu et al ${ }^{14}$ determined MTD to be $210 \mathrm{mg} / \mathrm{m}^{2}$ for $* 28 / * 28$ genotypes, while Kim et al $^{12}$ determined MTD to be $240 \mathrm{mg} / \mathrm{m}^{2}$ for $* 6$ and $* 28$ homozygous genotypes. Innocenti et al $^{13}$ utilized flat dosing based on a standard body surface area
(BSA) of $1.8 \mathrm{~m}^{2}$ and determined MTD for $* 28 / * 28$ to be $400 \mathrm{mg}$ (equivalent to $220 \mathrm{mg} / \mathrm{m}^{2}$ ) when irinotecan was used as monotherapy administered every 3 weeks. In all studies, MTD for wild type alleles was higher than for homozygous variant alleles. The two studies by Toffoli et $\mathrm{a}^{8,15}$ only investigated the *1/*28 genotypes compared to wild-type and found that patients with only one variant allele require lower irinotecan doses as well.

Tumor response was also evaluated in six studies as a secondary endpoint. ${ }^{8,9,11-13,15}$ In the Kim et al12 and Marcuello et al9 studies, overall response rate (ORR) decreased in patients who had two variant alleles (either $* 6$ or $* 28$ ). In Kim et al, patients with a wild-type allele had an ORR of $61.5 \%$, which decreased to $28.6 \%$ in patients with 2 variant alleles. However, patients with one variant allele had an increased ORR of $80 \%$. In Marcuello et al, the ORR for $* 1 / *_{1}, * 1 / *^{*} 8$ and $* 28 / *^{*} 8$ genotypes were $60 \%, 39 \%$ and $13 \%$, respectively. In the other four studies, tumor response was either not correlated with genotype or efficacy results were inconclusive. (Table II) 
Table II

Summary of Results

\begin{tabular}{|c|c|c|c|c|c|}
\hline Name (year) & Study Population & $\begin{array}{l}\text { Sample } \\
\text { Size }\end{array}$ & $\begin{array}{l}\text { Genotypes } \\
\text { Included }\end{array}$ & Regimen & Results (reported as MTD) \\
\hline $\begin{array}{l}\text { Toffoli et al } \\
\text { (2010) }\end{array}$ & $\begin{array}{l}\text { Patients with } \\
\text { mCRC }\end{array}$ & $n=59$ & $\begin{array}{l}\text { UGT1A1 } \\
* 1 /{ }^{*} 1, * 1 / * 28\end{array}$ & FOLFIRI & $\begin{array}{l}* 1 / * 1-370 \mathrm{mg} / \mathrm{m}^{2} \\
* 1 / * 28-310 \mathrm{mg} / \mathrm{m}^{2}\end{array}$ \\
\hline $\begin{array}{l}\text { Marcuello et al }{ }^{9} \\
\text { (2011) }\end{array}$ & $\begin{array}{l}\text { Patients with } \\
\text { mCRC or locally } \\
\text { advanced } \\
\text { recurrence after } \\
\text { surgery }\end{array}$ & $\mathrm{n}=94$ & $\begin{array}{l}\text { UGT1A1 } \\
* 1 / * 1, * 1 / * 28 \\
* 28 / * 28\end{array}$ & FOLFIRI & $\begin{array}{l}* 1 / * 1-180 \mathrm{mg} / \mathrm{m}^{2} \\
* 1 / * 28-110 \mathrm{mg} / \mathrm{m}^{2} \\
* 28 / * 28-90 \mathrm{mg} / \mathrm{m}^{2}\end{array}$ \\
\hline $\begin{array}{l}\text { Satoh et } \mathrm{al}^{10} \\
(2011)\end{array}$ & $\begin{array}{l}\text { Patients with } \\
\text { histologically } \\
\text { confirmed and } \\
\text { inoperable } \\
\text { mCRC }\end{array}$ & $\mathrm{n}=82$ & $\begin{array}{l}\text { UGT1A1 } \\
* 1 / *^{*} 1,{ }^{*} 1 / 28, \\
* 1 / * 6, \\
* 28 /{ }^{*} 28, \\
* 6 / * 6\end{array}$ & $\begin{array}{l}\text { Irinotecan } \\
\text { monotherapy } \\
\text { every } 14 \text { days }\end{array}$ & $\begin{array}{l}*^{*} 1 / * 1,>150 \mathrm{mg} / \mathrm{m}^{2} \\
* 1 / * 6, * 1 / * 28->150 \mathrm{mg} / \mathrm{m}^{2} \\
* 6 / * 6, * 28 / * 28-150 \mathrm{mg} / \mathrm{m}^{2}\end{array}$ \\
\hline $\begin{array}{l}\text { Goetz et al }{ }^{11} \\
(2013)\end{array}$ & $\begin{array}{l}\text { Patients with } \\
\text { metastatic or } \\
\text { locally advanced } \\
\text { cancer }\end{array}$ & $\mathrm{n}=53$ & $\begin{array}{l}\text { UGT1A1 } \\
* 1 / * 1, * 1 / * 28 \\
* 28 / * 28\end{array}$ & CAPIRINOX & $\begin{array}{l}{ }^{*} 1 / *^{*}-\text { irinotecan } 150 \mathrm{mg} / \mathrm{m}^{2}, \\
\text { oxaliplatin } 100 \mathrm{mg} / \mathrm{m}^{2}, \text { capecitabine } \\
1600 \mathrm{mg} / \mathrm{m}^{2} \\
{ }^{*} 1 /{ }^{*} 28 \text { - irinotecan } 150 \mathrm{mg} / \mathrm{m}^{2}, \\
\text { oxaliplatin } 85 \mathrm{mg} / \mathrm{m}^{2}, \text { capecitabine } \\
400 \mathrm{mg} / \mathrm{m}^{2} \\
{ }^{*} 28 / * 28 \text { - irinotecan } 75 \mathrm{mg} / \mathrm{m}^{2} \text {, } \\
\text { oxaliplatin } 85 \mathrm{mg} / \mathrm{m}^{2}, \text { capecitabine } \\
400 \mathrm{mg} / \mathrm{m}^{2}\end{array}$ \\
\hline $\begin{array}{l}\text { Kim et } \mathrm{al}^{12} \\
(2013)\end{array}$ & $\begin{array}{l}\text { Patients with } \\
\text { mCRC }\end{array}$ & $n=50$ & $\begin{array}{l}\text { UGT1A1 } \\
* 1 / *^{*} 1,{ }^{*} 1 /{ }^{*} 28, \\
* 1 / * 6, \\
* 28 /{ }^{*} 28, \\
* 6 / * 6, * 6 / * 28\end{array}$ & XELIRI & $\begin{array}{l}* 1 / * 1-380 \mathrm{mg} / \mathrm{m}^{2} \\
* 1 / * 6,{ }^{*} 1 / * 28-380 \mathrm{mg} / \mathrm{m}^{2} \\
* 6 / * 6, * 6 / * 28,{ }^{*} 28 / * 28-240 \\
\mathrm{mg} / \mathrm{m}^{2}\end{array}$ \\
\hline $\begin{array}{l}\text { Innocenti et al }{ }^{13} \\
(2014)\end{array}$ & $\begin{array}{l}\text { Patients with } \\
\text { histologically } \\
\text { confirmed solid } \\
\text { tumors or } \\
\text { lymphoma } \\
\text { refractory to } \\
\text { standard therapy } \\
\end{array}$ & $n=68$ & $\begin{array}{l}\text { UGT1A1 } \\
* 1 / * 1, * 1 / * 28, \\
* 28 / * 28\end{array}$ & $\begin{array}{l}\text { Irinotecan } \\
\text { monotherapy } \\
\text { every } 21 \text { days }\end{array}$ & $\begin{array}{l}* 1 /{ }^{*} 1-850 \mathrm{mg}\left(470 \mathrm{mg} / \mathrm{m}^{2 *}\right) \\
* 1 /{ }^{*} 28-700 \mathrm{mg}\left(390 \mathrm{mg} / \mathrm{m}^{2 *}\right) \\
* 28 /{ }^{*} 28-400 \mathrm{mg}\left(220 \mathrm{mg} / \mathrm{m}^{2 *}\right) \\
\text { *based on a standardized BSA of } \\
1.8 \mathrm{~m}^{2}\end{array}$ \\
\hline $\begin{array}{l}\text { Lu et al }{ }^{14} \\
\text { (2014) }\end{array}$ & $\begin{array}{l}\text { Patients with } \\
\text { mCRC }\end{array}$ & $\mathrm{n}=107$ & $\begin{array}{l}\text { UGT1A1 } \\
* 1 / * 1, * 1 / * 28, \\
* 28 / * 28\end{array}$ & $\begin{array}{l}\text { FOLFIRI + } \\
\text { bevacizumab }\end{array}$ & $\begin{array}{l}* 1 / * 1-260 \mathrm{mg} / \mathrm{m}^{2} \\
* 1 /{ }^{*} 28-240 \mathrm{mg} / \mathrm{m}^{2} \\
* 28 / * 28-210 \mathrm{mg} / \mathrm{m}^{2}\end{array}$ \\
\hline $\begin{array}{l}\text { Toffoli et al }{ }^{15} \\
(2017)\end{array}$ & $\begin{array}{l}\text { Patients with } \\
\text { mCRC }\end{array}$ & $\mathrm{n}=48$ & $\begin{array}{l}\text { UGT1A1 } \\
* 1 / * 1, * 1 / * 28\end{array}$ & $\begin{array}{l}\text { FOLFIRI + } \\
\text { bevacizumab }\end{array}$ & $\begin{array}{l}* 1 / *_{1}-310 \mathrm{mg} / \mathrm{m}^{2} \\
* 1 / *^{2} 2-260 \mathrm{mg} / \mathrm{m}^{2}\end{array}$ \\
\hline
\end{tabular}




\section{Discussion}

Although the FDA label did not provide specific guidance for dosage adjustment, the Dutch Pharmacogenomics Working Group (DPWG) recommended to reduce the initial starting dose of irinotecan by $30 \%$ of the standard dose if the patient has a homozygous variant genotype. ${ }^{18}$ However, the difference in MTD for wild type vs. homozygous variant genotype seen in the studies of this review was often greater than $30 \%$, suggesting a more conservative initial dose may be warranted. Furthermore, neither the FDA nor the DPWG addressed * 6 alleles. The studies included in this review investigated patients with both *28 and *6 genotypes, which may allow for increased generalizability. The studies did not address any significant differences in response to irinotecan between $* 6 / * 6$ vs. $* 28 / * 28$ genotypes, so it may be reasonable to treat these patients similarly although more literature would be required to provide a complete comparison.

Dosing recommendations ranged widely between the studies examined in this review. Much of the variability may be attributed to the heterogeneity of the studies with respect to the demographics of the study samples, the definitions used for MTD and the chemotherapy regimen utilized. The inclusion and exclusion criteria varied between the studies. An Eastern Cooperative Oncology Group (ECOG) ${ }^{19}$ score of $0-2$ was a requirement for eligibility for most studies (although some used $0-1)$ but patients' various comorbidities may have influenced tolerance of irinotecan since not all studies excluded the same conditions. Concomitant use of chemotherapy agents in the regimen that also are associated with severe neutropenia and diarrhea may decrease the tolerability of irinotecan. For example, irinotecan dosing recommendations were lowest in the study by Goetz et $\mathrm{al}^{13}$ which may be due to the concomitant administration of oxaliplatin and capecitabine which can also both significantly contribute to neutropenia.

Frequency of administration may also affect recommended doses. A review by Hoskins et al found that irinotecan toxicity was not associated with genotype at lower doses, such as $<150$ $\mathrm{mg} / \mathrm{m}^{2}{ }^{20}$ Similarly, a meta-analysis by Hu et al found that there was no association between genotype and irinotecan induced diarrhea at irinotecan doses $<125 \mathrm{mg} / \mathrm{m}^{2}{ }^{21}$ This suggests that genotype may not be as significant of a factor for regimens where irinotecan is given weekly since doses tend to be lower than with regimens where irinotecan is administered every 2 or 3 weeks.

Several studies in this review also performed tumor response assessments and found that response rate was lower with the reduced doses recommended for variant allele genotypes. Therefore, it is also essential to ensure efficacy is not compromised when adjusting the dose based on genotype. Although more studies that are designed to evaluate efficacy are needed to fully understand the relationship, clinicians may choose to initiate treatment at doses higher than the MTDs established in these studies and utilize supportive care to manage adverse effects rather than risk inadequate response with lower dosages. Moreover, a secondary finding from this literature review was that the MTDs for patients with wild-type alleles were often significantly higher than standard doses of irinotecan. This suggests that these patients may be able to tolerate doses higher than what is used in clinical practice, which may lead to increased tumor responses.

If patients are known to have homozygous variant alleles, it may be appropriate to utilize alternative therapies if available to decrease risk of an unfavorable safety profile or inadequate response. However, irinotecan is an inexpensive and widely used cytotoxic agent that is first line therapy for various cancers, such as mCRC. The benefits of use, even in homozygous $* 6$ or $* 28$ patients, may outweigh the risks as long as patients are carefully managed with supportive care.

\section{Conclusion}

These findings add to a growing body of literature that suggests patients with UGT1A1 *6 or *28 variant alleles benefit from lower doses of irinotecan. However, due to the heterogeneity of currently available studies, more evidence that investigates various regimens in different patient populations is needed to determine the most appropriate dosing strategies. Although other factors as well as efficacy considerations will likely influence clinical decision making, genotype may be an important factor when determining dose. As the field of pharmacogenomics rapidly advances, further developments in the literature driven by more robust studies will serve to guide clinicians with regard to UGT1A1 genotypes and lead to improved patient outcomes.

The authors have no disclosures or conflicts of interest to report

\section{References}

1. Irinotecan Pathway, Pharmacokinetics. PharmGKB.org. https://pharmgkb.org/pathway/PA2001

2. Strassburg C. Pharmacogenetics of Gilbert's syndrome. Pharmacogenomics. 2008 Jun; 9(6):70315

3. Iyer $L$, Das $S$, Janisch L et al. UGT1A1*28 polymorphism as a determinant of irinotecan disposition and toxicity. The Pharmacogenomics Journal. 2002; 2:43-47.

4. Barbarino J, Haidar C, Klein T et al. PharmGKB summary: very important pharmacogene information for UGT1A1. Pharmacogenet Genomics. 2014 Mar; 24(3):177-83

5. Dean L. Irinotecan Therapy and UGT1A1 Genotype. Medical Genetics Summaries. 2015. 
6. Camptosar (irinotecan) [package insert]. New York, NY: Pfizer; 2005.

7. Yang $Y$, Zhou $M$, Hu $M$ et al. UGT1A1* 6 and UGT1A $1 * 28$ polymorphisms are correlated with irinotecan-induced toxicity: A meta-analysis. Asia-Pac J Clin Oncol. 2018; 14: e479- e489.

8. Toffoli G, Cecchin E, Gasparini G et al. Genotype driven phase I study of irinotecan administered in combination with fluorouracil/leucovorin in patients with metastatic colorectal cancer. J Clin Oncol. 2010 Feb; 28(5):866-871.

9. Marcuello E, Paez D, Pare L et al. A genotype directed phase I-IV dose finding study of irinotecan in combination with fluorouracil/leucovorin as first line treatment in advanced colorectal cancer. Br J Cancer. 2011 Jun; 105(1):53-57.

10. Satoh T, Ura T, Yamada Y et al. Genotype directed, dose finding study of irinotecan in cancer patients with UGT1A1*28 and/or UGT1A1*6 polymorphisms. Cancer Sci. 2011 Oct; 102(10):1868-1873.

11. Goetz M, McKean H, Reid J et al. UGT1A1 genotype guided phase I study of irinotecan, oxaliplatin and capecitabine. Invest New Drugs. 2013 Dec; 31(6).

12. Kim K, Kim H, Sym S et al. A UGT1A $1 * 28$ and *6 genotype directed phase I dose escalation trial of irinotecan with fixed dose capecitabine in Korean patients with metastatic colorectal cancer. Cancer Chemother Pharmacol. 2013; 71:1609-1617.

13. Innocenti F, Schilsky R, Ramirez J et al. Dose finding and pharmacokinetic study to optimize the dosing of irinotecan according to the UGT1A1 genotype of patients with cancer. J Clin Oncol. 2014 Aug; 32(22):2328-2334.
14. Lu C, Huang $\mathrm{C}, \mathrm{Hu} \mathrm{H}$. Prognostic advantage of irinotecan dose escalation according to uridine disphosphate glucuronosyltransferase 1A1 (UGT1A1) genotyping in patients with metastatic colorectal cancer treated with bevacizumab combined with 5fluorouracil/leucovorin with irinotecan in a first line setting. Translational Res. 164(2): 169-176.

15. Toffoli G, Sharma M, Marangon E et al. Genotype guided dosing study of FOLFIRI plus bevacizumab in metastatic colorectal cancer patients. Clin Cancer Res. 2017 Feb; 23(4): 918-924.

16. Common Terminology Criteria for Adverse Events. Nih.gov.

https://ctep.cancer.gov/protocolDevelopment/electr onic_applications/ctc.htm

17. Researchgate.net. https://www.researchgate.net/figure/The-3-3-doseescalation-study-design-DLT-dose-limiting-toxicityMTD-maximum_fig1_327291429

18. Annotations of DPWG guideline for irinotecan and UGT1A1. PharmGKB. 2018 Nov. Accessed at https://www.pharmgkb.org/guidelineAnnotation/PA 166104951

19. ECOG Performance Status. Ecog-acrin.org. https://ecog-acrin.org/resources/ecog-performancestatus

20. Hoskins J, Goldberg R, Qu P et al. UGT1A1*28 Genotype and Irinotecan Induced Neutropenia: Dose Matters. J Natl Cancer Inst. 2007; 99:1290-5.

21. Hu Z, Yu Q, Zhao Y. Dose dependent association between UGT1A1*28 polymorphism and irinotecan induced diarrhea: A meta analysis. Eur J Cancer. 2010. 1856-65. 